\title{
«Vencido me tiene el dulçor de tu suave canto»: Melibea y la imagen de la sirena
}

\author{
Ivette Martí Caloca \\ Universitad de Puerto Rico, Recinto de Río Piedras
}

\section{RESUMEN}

En el Auto XI, Pármeno teme que el primer encuentro con Melibea desemboque en peligro, por lo que la compara con una sirena. Sus palabras resultan ser proféticas, especialmente si tomamos en cuenta que no solo es él quien muere. Al final, la doncella prueba ser tan fascinante, peligrosa y letal como las sirenas con las que se le compara..

Palabras Clave: Melibea, sirena, canto, intuición, muerte.

\section{"Vencido me tiene el dulçor de tu suave canto»: Melibea and the image of the Siren}

\section{ABSTRACT}

In the eleventh act, Pármeno fears that the first encounter with Melibea will lead to danger, for which he compares her to a siren. His words turn out to be prophetic, especially since he is not the only one who dies. In the end, the maiden proves to be as fascinating, dangerous and lethal as the sirens with which she is compared.

KeY WORDs: Melibea, siren, singing, intuition, death.

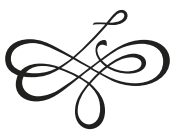


En el Auto VII de la Tragicomedia, Celestina le lanza sus sagaces halagos a Areúsa para que consienta entregarse sexualmente a Pármeno. Entre los remilgos de la joven, la experta alcahueta la pretende lisonjear comparándola con una sirena: "Pues no estés asentada; acuéstate y métete debaxo de la ropa, que paresces serena». (VII 371). ${ }^{1}$ Sin embargo, bajo esta adulación subyace una mordaz ironía dramática, pues este requiebro de Celestina pronostica la muerte del alevoso sirviente. Según observa atinadamente George A. Shipley:

The reference is in this case first of all a device for flattery; characters and readers alike accept it as an elevating visual image and an allusion to Areúsa's attractive charms. But the author's caustic irony is at work even in this passing compliment, for subsequent action proves the image more deeply allusive. Under Celestina's supervision the girl plays out the siren's role, luring Pármeno into her embrace and the bawd's control, ensuring his eventual destruction. (1982: 214-5)

En este sentido, Vicenta Blay Manzanera y Dorothy Sherman Severin observan que «the connection between Parmeno's seduction by the siren and his impending death must be intentional» (1999: 17-8). En palabras de María Eugenia Díaz Tena: «La simple visión de la sirena Areúsa le atrae de forma inevitable y esa pasión irrefrenable le conducirá a la muerte, pues el hecho de conseguir sexualmente a Areúsa conlleva que el joven Pármeno tenga que asociarse con el codicioso Sempronio y la avara Celestina» (2012: 91).

Muy bien podríamos argumentar que el destino de Pármeno queda servido al unirse amorosamente a Areúsa, pues su salto a la cama de la bella prostituta lo envuelve en un vórtice mortal. Aun así, no es a esta a quien únicamente debe temer el mozo, pues frente a él se alza otra amenaza todavía más letal, Melibea. ${ }^{2}$ Así pues, cuando en el Auto XI escucha que Celestina le refiere a su señor la feliz noticia de que la doncella al fin lo espera esa noche, comenta despavorido:

Mucha sospecha me pone el presto conceder de aquella señora y venir tan aýna en todo su querer de Celestina, engañando nuestra voluntad con sus palabras dulces

1.- Citaré siempre de la edición de Peter E. Russell incluida en la bibliografía, indicando al final el auto y el número de la página.

2.- Hay diversos puntos de comparación entre los fascinantes personajes de Melibea y Areúsa. Varios estudiosos se han ocupado de observar al menos algunos aspectos: Maravall (1964: 106-7), Castro (1965: 111), Lacarra (1986: 17), Lacarra Lanz (2001: 93 y passim) y (2005), Abril-Sánchez (2003), Ciplijauskaité (2004: 20 y passim), Ramírez Santacruz (2004), Cantalapiedra Erostarbe (2006: 73 y passim), Deyermond (2008: 78), Martínez (2010), Gerli (2011: 156) y Díaz Tena (2012). 
y prestas, por hurtar por otra parte, como hazen los de Egito quando el signo nos catan en la mano. Pues alahé, madre, con dulces palabras están muchas injurias vengadas. El falso boyzuelo con su blando cencerrar trae las perdizes a la red; el canto de la serena engaña los simples marineros con su dulçor. Assí ésta, con su mansedumbre y concessión presta, querrá tomar una manada de nosotros a su salvo; purgará su inocencia con la honrra de Calisto y con nuestra muerte. Assí, como corderica mansa que mama su madre y la agena, ella con su segurar tomará la venganza de Calisto en todos nosotros, de manera que, con la mucha gente que tiene podrá caçar a padres y hijos en una nidada, y tú estarte has rascando a tu fuego, diciendo: «a salvo está el que repica». (XI 450-1)

El peligro que Pármeno percibe ante la posibilidad de enfrentarse a Melibea no solo se convertirá en otra de las interesantes instancias de ironía dramática en la Tragicomedia, sino que es mucho más. Allende su cobardía, este parlamento nos abre un pequeño portillo a su subconsciente al cual accedemos a través de sus perspicaces palabras. La atemorizante imagen de Melibea que se desprende de ellas muestra su aguda intuición de que se enfrentará a un ser peligroso. Razón tenía para que su imaginación febril convirtiera a la dama de su señor en una atemorizante sirena. ${ }^{3}$ Vale recordar que el hijo de Claudina encuentra su fin precisamente luego de que se concreta el temido encuentro en el Auto XII. Además, las circunstancias de esa muerte son muy reveladoras, pues él y su secuaz se descalabran al arrojarse por la ventana de Celestina para seguidamente morir descabezados por la justicia. Según el testimonio de Sosia:

¡O señor, que si los vieras, quebraras el coraçón de dolor! El uno llevava todos los sesos de la cabeça de fuera, sin ningún sentido; el otro, quebrados entramos braços y la cara magullada. Todos llenos de sangre; que saltaron de unas ventanas muy altas por huyr del alguazil. Y assí, casi muertos, les cortaron las cabeças, que creo que ya no sintieron nada. (XIII 492-3)

Su terrible final recuerda de alguna manera el de las víctimas despedazadas por las sirenas. No solo se "quiebra» por la caída, sino que, en cierto sentido, si tomamos en cuenta que decapitar es cercenar un miembro, es decir, desmembrar, entonces simbólicamente se cumple su augurado temor.

Como se sabe, las sirenas eran atroces. Circe previene a Odiseo de su amenaza en el Canto XII de su epopeya:

3.- Para Deyermond, la imagen le viene a Pármeno del recuerdo de escuchar a Celestina lisonjeando a Areúsa (2001: 172). 
Llegarás primero a las sirenas que encantan a cuantos hombres van a su encuentro. Aquel que imprudentemente se acerca a ellas y oye su voz, ya no vuelve a ver a su esposa ni a sus hijos pequeñuelos rodeándole, llenos de júbilo, cuando torna a su hogar, sino que le hechizan con el sonoro canto sentadas en una pradera y teniendo a su alrededor enorme montón de huesos de hombres putrefactos cuya piel se va consumiendo. (Homero 206)

Además, Plinio nos advierte: «Nec sirenes impetraverint fidem, adfirmet licet Dinon Clitarchi celebrati auctoris pater in India esse mulcerique earum cantu quos gravatos somno lacerent» (Rackman 1983: X.LXX 136, 380). ${ }^{4}$ Estas se concebían como criaturas terroríficas y sangrientas. Sin embargo, también eran hábiles seductoras. Según establece Massimo Izzi: «Detrás de [... la belleza de las sirenas], aparentemente inocuo, se esconde el miedo fundamental del hombre ante las valencias típicas de la feminidad» (2000: 447). En el caso de nuestra joven protagonista, Blay Manzanera y Severin sostienen: "The siren, associated with [...] Melibea [...] represent[s] the threat of female sexuality» (1999: 29). Como bien apunta Michael Gerli, la «sirena [es un] antiguo símbolo del deseo prohibido, irresistible y destructor» (2009: 203). Y es que el poder de seducción de estas singulares criaturas llevaba a los marinos a su fin pues, fascinados por sus melodías, se lanzaban al abismo y terminaban violentamente desmembrados por ellas. La muerte de Pármeno parece evocar aquellos descuartizamientos. Más aún, el contacto que tienen en esa fatal noche con Melibea es desde el otro lado de una puerta, es decir, que a lo que se enfrentan Calisto y sus sirvientes es al sonido de la voz "dulce» (XII 462) $\mathrm{y}$ «suave» (XII 465) de la doncella. Melibea, entonces, se nos va dibujando como un ser monstruoso, peligroso y fascinante. Al utilizar este símil, Pármeno la intuye de una manera muy elocuente.

Por añadidura, justo antes de aludir a estas temibles cantoras, el pavoroso sirviente también teme que Melibea sea como el falso boezuelo que con su «blando cencerrar» logra apresar a las inocentes perdices. Igual que las sirenas con su dulce canto, este embaucador atrae a las ingenuas avecillas con sus sutiles campanadas. En este sentido, Michael Gerli advierte: "For the sixteenth-century reader, both the mermaid and the pantomime ox share the ability to enchant with sound: the one with its tinkling bell deceives the quarry into believing the stalker is yet another benign grazing animal; and the other with her hypnotic song and promises of sexual delights». (1988: 56). El estudioso afirma que hay una insinuación sexual que no solo subyace en la comparación que hace Pármeno entre la

4.- "Nor should the sirens obtain credit, although Dinon the father of the celebrated authority Clitarchus declares that they exist in India and that they charm people with their song and then when they are sunk in a heavy sleep tear them to pieces» (Rackman 1983: 381). 
doncella y este mimo, sino también en la que hace entre esta y una sirena. ${ }^{5}$ Ulteriormente, la atracción que ejerce Melibea será igual de letal que el de estas atemorizantes y cruentas criaturas míticas.

Según lo que venimos viendo, no debe extrañarnos demasiado que el último encuentro entre los amantes antes de su augurada muerte comience en canto. De la misma manera que las sirenas aguardan quedas a sus cándidas víctimas a quienes atraen con sus hermosas melodías, la hija de Pleberio espera pacientemente a Calisto en el Auto XIX entonando unas sórdidas y sugerentes cancioncillas con su sirvienta. Esta pareja de cantoras nos recuerda que no solo Sófocles se refiere a un dúo, ${ }^{6}$ sino que desde la propia Odisea son precisamente dos sirenas las que intentan -aunque infructuosamente — seducir al astuto rey de Ítaca y su tripulación. Ahora bien, en una de las insinuantes estrofas que canta Lucrecia se subrayan las cualidades depredadoras de su señora cuando la compara con un lobo hambriento atisbando con regocijo a su inocente presa:

\section{Saltos de gozo infinitos da el lobo viendo ganado; con las tetas los cabritos; Melibea, con su amado. ${ }^{8}$}

(XIX 567)

Del mismo modo que las sirenas frente a los indefensos marinos cautivados por sus encantadoras voces, el lobo se goza al ver el desvalido ganado que le satisfará el apetito. ${ }^{9}$ Por lo tanto, al igual que Pármeno, Lucrecia

5.- Contrariamente, Nicasio Salvador Miguel establece: «Rojas [...] adapta la imagen [del boezuelo] a un nuevo contexto en el que Pármeno medita sobre la inautenticidad y la capacidad de engaño de Melibea, características que resalta mediante el adjetivo "falso" y el despectivo «boezuelo». Por eso, la referencia va seguida inmediatamente a otra de las sirenas, símbolo de las mismas notas, aunque precedida de otra imagen animalística con la misma intención, en boca de Sempronio: «las zarazas en pan envueltas». En una palabra, las intervenciones de ambos criados, con las distintas menciones de animales, persiguen insistir en el contraste entre la realidad y las apariencias para poner en guardia a Calisto sobre el comportamiento de Melibea, sin que se adviertan ni por el forro las «sexual connotations of Pármeno's comparison of Melibea to the pantomime ox» (1993: 65).

6.- Más adelante se les comienza a idear como un trío, o hasta como un cuarteto. En cierto sentido, si contamos a Areúsa como otra sirena según la comparación que hace Celestina, entonces sumamos tres.

7.- Interesantemente, esta decepción las hace suicidarse.

8.- Para un estudio de estas canciones véase Martí Caloca (2017).

9.- Muchos estudiosos ven a la doncella como presa de Calisto. Alphonse Vermeylen, por ejemplo, sugiere que "Melibea es la que se somete por entero a Calisto». (1990: 104). Es más, el estudioso añade que "[e]l canto interrumpido por éste, desde las primeras estrofas cantadas por Lucrecia a petición de su ama y hasta su final que son las estrofas cantadas por Melibea sola, es todo un grito de exaltada sumisión de la mujer respecto al caballero» (1990: 104). Para María Eugenia Lacarra, "cuando Calisto se le acerca finalmente, Melibea es la presa y Calisto el depredador. Esto ya se intuía en la canción, al aludir a los saltos del lobo aunque esté un tanto incierto si el lobo era Calisto o Melibea era la loba» (1996: 431). 
hace una penetrante analogía mediante la cual convierte a su ama en una perniciosa depredadora y que resultará ser cónsona con su identidad metafórica de sirena.

Prestamente, la voz de la sirvienta se funde con la de su señora, ahora en unas estrofas mucho más dulces y serenas, y que Melibea concluye sola. Así, su amante alcanza a escucharla y desciende al huerto "vencido» por la melodía. ${ }^{10}$ Es entonces cuando la dama denuncia las licencias que su criada se atribuye con Calisto de una manera muy singular y elocuente: «Lucrecia, ¿qué sientes, amiga? ¿Tórnaste loca de plazer? Déxamele, no me le despedaces» (Suplo el énfasis/ XIX 570). Como vemos, la señora reprende el comportamiento inapropiado de su sirvienta con una metáfora que nos devuelve enseguida a la manera en la que las sirenas mataban a sus víctimas, es decir, despedazándolas, pues no es a Lucrecia a quien corresponderá esta faena. Es más, justo cuando halaga en esta ocasión a Melibea por su canto, Calisto se precipita hacia ella por última vez, para muy pronto encontrar su muerte. Después de todo, bien lo dijo Shipley cuando observó:

The splendid verses that grace the lovers last meeting, in Act XIX, prove to all her audience that Melibea (who is in a limited sense responsible for the series of deaths) indeed also has the sweet voice of a siren and sings alluringly: «Vencido me tiene el dulzor de tu suave canto,» says Calisto as he moves towards his last embrace. (Énfasis suplido/ 1982: 215)

En consecuencia, se confirma la desasosegante premonición de Pármeno en la que Melibea deviene sirena de canto letal. A ello debemos sumar que ya Calisto nos la había descrito desde el primer auto utilizando como comparación otro monstruo mitológico híbrido que, al igual que las sirenas, ejerce un irresistible poder de seducción que lleva a la muerte. El retrato de dama tradicional culmina en una imagen igual de temible que la de las sirenas:

Comienço por los cabellos. ¿Ves tú las madexas del oro delgado que hilan en Arabia? Más lindos son, y no resplandecen menos. Su longura hasta el postrero assiento de sus pies; después crinados y atados con la delgada cuerda como ella se los pone, no ha más menester para convertir a los hombres en piedras. (I 230-1)

10.- Vale aquí recordar que el nombre de Melibea evoca la melosidad de su voz, aunque esta sienta reparo en ello. Véanse en especial Vermeylen (1990 : 105), Cherchi (1997: 82-83), K. y T. Reichenberger (2001: 230-231), Reinchenberger y Stegmann (2001: 253). 
El poder de petrificar que Calisto le adjudica a Melibea la convierte metafóricamente en la Gorgona. ${ }^{11}$ Por lo tanto, no es solo el antiguo pupilo de Celestina quien habrá de intuir el peligro que supone Melibea, sino que Calisto, de manera similar, manifiesta desde el inicio el temor subconsciente y la fascinación que ella le produce. Por su parte, Luis Galván también recuerda este piropo ambivalente, pero para resaltar que, como muy bien lo percibió, Calisto termina convertido en piedra, si bien de manera simbólica:

A este imaginado descenso por la escala del ser sigue un descenso físico. El golpe estaba anunciado desde el principio. Calisto sabía que los cabellos de Melibea, tan hermosos, eran capaces de "convertir los hombres en piedras» (I, p.44). En la Celestina es imposible que se produzca literalmente tal metamorfosis; pero cabe una versión desplazada, realista, como la que ofrece el lamento de Tristán: «iOh mi señor y mi bien muerto, oh mi señor despeñado!... Coge, Sosia, esos sesos de esos cantos; júntalos con la cabeza del desdichado amo nuestro» (XIX, p. 324). Melibea, al informar a su padre, no olvida este detalle: "puso el pie en vacío y cayó, y de la triste caída sus más escondidos sesos quedaron repartidos por las piedras y paredes» (XX, p. 333). Calisto va a parar a "la tierra» (XX, p. 332), y Melibea se llama a sí misma, al concluir, "este cuerpo que allá baja» (XX, p. 335). Así pues, el tipo de muerte que sufren los enamorados es un paso más en el proceso que han seguido: tras abandonar o vaciar de sentido el campo celestial, habiendo asumido lo animal y la cosificación inherentes a su comportamiento, ahora se unen a la ínfima materia inerte, la tierra y las piedras. (2005: 470)

También podríamos decir que Melibea, como las sirenas, despedazará metafóricamente a su amante cuyos sesos se desparraman en los muros que cercan su huerto poco después de haberse lanzado a ella tras escuchar su canto. Pero este no será el último momento en el que la voz de Melibea pruebe ser fatal. Antes de morir le pide a su padre: «manda traer algún instrumento de cuerdas con que sufra mi dolor, o tañiendo, o cantando, de manera que, aunque aquexe por una parte la fuerça de su acidente, mitigarlo han por otra los dulces sones y alegre armonía». (XX 582). Aunque, como ella misma expone en su soliloquio, se trate de una excusa para que la dejen sola, y aunque finalmente no llegue a hacer-

11.- Para la relación entre Melibea y Medusa, véanse Garci-Gómez (1990), Cárdenas (1990: 90), Galván (2005: 470) y Martí Caloca (2012) y (2019). 
lo de manera concreta, su monólogo final termina siendo una especie de último "canto» que precede la muerte metafórica del padre que sufre sin consuelo el suicidio de su amada hija. Así pues, Melibea cumple la premonición de Pármeno. Su intuición - como la de Lucrecia y Calisto- no lo engañaba. Finalmente, ella termina siendo, como las sirenas, causa de terror, fascinación y muerte.

\section{Bibliografía}

ABRIL-SÁNCHEZ, Jorge (2003), «Una familia de meretrices: prostitutas públicas y privadas, cortesanas, rameras y putas viejas en La Celestina», Celestinesca 27, pp. 7-24.

Blay Manzanera, Vicenta y Dorothy Sherman Severin (1999), Animals in "Celestina", Vol. 18. Department of Hispanic Studies, Queen Mary and Westfield College.

Cantalapiedra Erostarbe, Fernando (2006), "Alisa y Celestina, las comadres de la tenería» en Estudios sobre lengua, literatura y mujer. $\mathrm{M}^{a}$ Isabel Sancho Rodríguez, Lourdes Ruiz Solves y Francisco Gutiérrez García. Jaén, Universidad de Jaén, pp. 63-130.

CÁRDEnAS, Anthony J. (1990), "Interpretación de asno: signo de la bestialidad humana en La Celestina», Texto crítico 16.42-43, pp. 85-95.

Castro, Américo. (1965), "La Celestina" como contienda literaria (castas y casticismos), Madrid, Revista de Occidente.

Cherchi, Paolo (1997), "Onomástica celestinesca y la tragedia del saber inútil» en Cinco siglos de "Celestina»: aportaciones interpretativas. Rafael Beltrán y José Luis Canet, eds., Valencia, Universitat de València, pp. 77-90.

CiplijausKaITÉ, Biruté (2004), "Juegos de duplicación e inversión en La Celestina» en La construcción del yo femenino en la literatura. Cádiz, Universidad de Cádiz, pp. 19-29.

Deyermond, Alan (2008), "Hacia una lectura feminista de la Celestina», Medievalia 40. Estudios de Alan Deyermond sobre "La Celestina" In Memoriam, pp. 74-85.

- (2001), "Sirenas del cancionero folklórico de México y su ascendencia medieval», Anuario de letras: Lingüística y filología 39, pp. 163-197.

Díaz Tena, María Eugenia (2012), "Que paresces serena», Celestinesca 36, pp. 71-102.

GaLVÁn, Luis (julio-diciembre 2005), «Imágenes y anagnórisis en La Celestina». Nueva Revista de Filología Hispánica 53.2, pp. 457-479.

Garci-Gómez, Miguel (1990), «El cabello de Melibea (Medusa): entre la petrificación y el emborricamiento» en Estudios en homenaje a Enrique Ruiz-Fornells. Pennsylvania, ALDEEU Erie, pp. 233-9. 
Gerli, E. Michael (2011), Celestina and the Ends of Desire. Toronto, University of Toronto Press.

- (2009), "El placer de la mirada: voyeurismo, fetichismo y la movilización del deseo en Celestina» en El mundo social y cultural de "La Celestina». Actas del Congreso Internacional, Universidad de Navarra, junio, 2001, Ignacio Arellano y Jesús M. Usunáriz, eds., Mardid-Frankfurt, Iberoamericana-Vervuert, pp. 191-209.

- (1988), "A Propos the Pantomime Ox, Sexual Innuendo, and Fuddled Partridges: Yet more on Parmeno's Remark», Celestinesca 12.2, pp. 55-60.

HOMERo La Odisea. Barcelona, Edicomunicación, 1992.

IzzI, Massimo (2000), Diccionario ilustrado de los monstruos. Ángeles, diablos, ogros, dragones, sirenas y otras criaturas del imaginario. Badalona (Barcelona), J. de Olañeta.

LacarRa Lanz, Eukene (1996), "Sobre los 'dichos lascivos y rientes' en Celestina» en Nunca fue pena mayor. Estudios de Literatura española en homenaje a Brian Dutton, Ana Menéndez Collera y Victoriano Roncero López, eds., Cuenca, Ediciones de la Universidad de Castilla-La Mancha, pp. 419-33.

- (1986), "Algunos datos para la historia de la misoginia en la Edad Media» en Studia in honorem prof. M. de Riquer I. Barcelona, Quaderns Crema, 1986, pp. 339-61.

- (2001), «Los amores citadinos de Calisto y Melibea», Celestinesca 25.12, pp. 83-100.

- (2005), "Las pasiones de Areúsa y Melibea» en "La Celestina» 14991999 Selected Papers from the International Congress in Commemoration of the Quincentennial Anniversary of La Celestina New York, November 1719, 1999. Ottavio DiCamillo y John O'Neill, eds., New York, Hispanic Seminary of Medieval Studies, pp. 75-109.

Maravall, José Antonio, (1964), El mundo social de "La Celestina", Madrid, Gredos.

Martí Caloca, Ivette (2012), "Melibea: eje de la scriptum ligata de La Celestina», Celestinesca 36, pp. 161-178.

- (2017), «'Saltos de gozo infinitos': Melibea como gran depredadora», eHumanista 35, pp. 296-310.

- (2019), "Todo se ha hecho a mi voluntad»: Melibea como eje central de "La Celestina", Madrid, Iberoamericana.

Martínez, María Victoria (2010), “¿Huerto cerrado' o ‘Puerta del diablo’? La mujer Eva y la mujer María en algunos textos de literatura castellana medieval», II Congreso Virtual sobre la Historia de las Mujeres (del 15 al 31 de octubre del 2010). <https://dialnet.unirioja.es/descarga/articulo/4095962.pdf». 
Rackman, H., ed. (1983), Natural History, de Plinio el Viejo, 3 vols. Edición bilingüe. Cambridge/Londres, Harvard University Press/William Heinemann LTD, Loeb Classical Library.

RAmírez SANTACRUZ, Francisco (otoño 2004), «Individualismo a ultranza en La Celestina: Areúsa y Melibea», Graffylia 2.4, pp. 64-71.

Reichenberger, Kurt y Theo Reichenberger (2001), «Fernando de Rojas como comentarista político: acerca de la elección de los nombres para los personajes de La Celestina», Tras los pasos de "La Celestina». Patricia Botta, Fernando Cantalapiedra, Kurt Reichenberger y Joseph T. Snow, Kassel: Edition Reichenberger, pp. 225-250.

Reichenberger, Kurt y Tilbert Stegmann (2001), «La denominació dels personatges de La Celestina en el seu context històric i polític». Tras los pasos de La Celestina. Patricia Botta, Fernando Cantalapiedra, Kurt Reichenberger y Joseph T. Snow, eds. Kassel, Edition Reichenberger, pp. 251-259.

RoJAS, Fernando de (1993), La Celestina, Comedia o Tragicomedia de Calisto y Melibea. Peter E. Russell, ed., Madrid, Clásicos Castalia.

Salvador Miguel, Nicasio (1993), "Otros bueyes que cazan perdices». Medievalismo 3, pp. 59-68.

Shipley, George A. (1982), "Bestiary Imagery in La Celestina», Revista de Estudios Hispánicos 9, pp. 211-218.

Vermeylen, Alphonse (1990), "Melibea y su 'voz de cisne'», Incipit 10, pp. $103-11$. 